\title{
Using Modified Clavien-Dindo's Classification System for Reporting Postoperative Complications of Transvesical Prostatectomy at Souro Sanou University Teaching Hospital of Bobo-Dioulasso (Burkina-Faso)
}

\author{
Adama Ouattara ${ }^{1 *}$, Abdoul Karim Paré ${ }^{1}$, Aristide F Kaboré2, Boukary Kabré2, Amidou Bako and \\ Mickael Rouamba ${ }^{1}$
}

${ }^{1}$ Division of Urology, Souro Sanou University Teaching Hospital, Bobo-Dioulasso, Burkina Faso

${ }^{2}$ Division of Urology, Yalgado Ouedraogo University Teaching Hospital, Ouagadougou, Burkina Faso

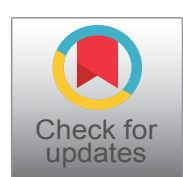

*Corresponding author: Adama Ouattara, Senior Lecturer in Urology, Division of Urology, Souro Sanou University Teaching Hospital, P.O. Box: 1465 Bobo-Dioulasso, Burkina Faso

\begin{abstract}
Aims: The aim of this study was to evaluate the postoperative complications using a standardized classification; modified Clavien's classification.

Patients and methods: We have included all patients aged at least 50 -years-old on the day of surgery between the $1^{\text {st }}$ June 2015 and $31^{\text {st }}$ May 2017 at the urology division of Souro Sanou University Teaching Hospital of Bobo-Dioulasso. Complications reports were performed according to the modified Clavien-Dindo system.

Results: Hundred patients (100) presenting a complication after BPH surgery were included in this study in a total of 312 open prostatectomies performed. The postoperative complication rate was $32 \%$. Seventy percent of the patients had at least one complication. Grade I and Grade II complications according to the modified Clavien's classification system were the most represented (87\%). Two patients (2) died in the immediate postoperative period (Grade V). The presence of urethral catheter before surgery was identified as a risk factor for complication. A statistically significant difference was found in the group ICC > 2 (Charlson Index of Comorbidity) for age parameter in the occurrence of complication.

Conclusions: Open prostatectomy is associated with high morbidity in subjects with urinary catheters prior to surgery. Grade I and Grade II according to the modified Clavien's classification system were the most reported.
\end{abstract}

\section{Keywords}

Open prostatectomy, Postoperative, Complications

\section{Introduction}

Benign prostate hyperplasia (BPH) is the most common urinary problem of the elderly man due to the discomfort for which it is responsible [1]. Surgical management of BPH occupies an important place in the urological activity. Despite the advent of mini invasive treatment as transurethral resection of prostate (TURP), open prostatectomy, the oldest method of BPH treatment, has remained the treatment of choice of BPH in many developing countries [2,3]. Like any surgical technique, it is not free from complications. Clavien's classification system is an excellent tool of reporting complications associated with surgical procedures. It was used for the first time in 1992 on a case of cholecystectomy [4]. Modified in 2004, it was recommended in 2012 and is validated in 2017 by many scientific societies of urology for post-operative complications reports [5-7]. The aim of this study was to evaluate the post-operative complications of open prostatectomy in order to describe the associated factors.

\section{Patients and Methods}

Our study was retrospective and included all the medical records of the patients in whom open transvesical prostatectomy were performed with complications. Data have been collected from June $1^{\text {st }}, 2015$ to May $31^{\text {st }}, 2017$ at the urology division of Souro Sanou

Citation: Ouattara A, Paré AK, Kaboré AF, Kabré B, Bako A, et al. (2019) Using Modified Clavien-Dindo's Classification System for Reporting Postoperative Complications of Transvesical Prostatectomy at Souro Sanou University Teaching Hospital of Bobo-Dioulasso (Burkina-Faso). Int Arch Urol Complic 5:056. doi. org/10.23937/2469-5742/1510056

Accepted: April 24, 2019: Published: April 26, 2019

Copyright: (C) 2019 Ouattara A, et al. This is an open-access article distributed under the terms of the Creative Commons Attribution License, which permits unrestricted use, distribution, and reproduction in any medium, provided the original author and source are credited. 
University Teaching Hospital of Bobo-Dioulasso. The In-patients and out-patients register of the service, the operative procedure registers, medical records files were used for the collection of the data. Inclusion criteria were clinical observation, programmed open transvesical prostatectomy, and a minimum six months post-operative follow-up. All surgical procedures were performed by urologist surgeons or by senior resident assisted by the urologist surgeon. Fever has been defined by a temperature of at least $38{ }^{\circ} \mathrm{C}$. A level of hemoglobin $<9 \mathrm{~g} / \mathrm{dl}$ was selected for bleeding requiring blood transfusion. Transitory hematuria was defined as

Table 1: Charlson Index of comorbidity [8].

\begin{tabular}{|l|l|}
\hline Clinical condition & Weight \\
\hline 50-60 years old & 1 \\
\hline Myocardal infarction & 1 \\
\hline Congestive heart failure & 1 \\
\hline Peripheral vascular disease & 1 \\
\hline Cerebrovascular disease & 1 \\
\hline Dementia & 1 \\
\hline Chronic obstructive pulmonary disease & 1 \\
\hline Connective tissue disease & 1 \\
\hline Ulcer disease & 1 \\
\hline Mild liver disease & 1 \\
\hline Slight Diabetes without complication & 1 \\
\hline $61-70$ years old & 2 \\
\hline Hemiplegia & 2 \\
\hline Moderate to severe renal disease & 2 \\
\hline Diabetes with en-organ damage & 2 \\
\hline Tumors & 2 \\
\hline Leukemia & 2 \\
\hline Lymphoma & 2 \\
\hline $71-80$ years old & 3 \\
\hline Moderate to severe liver disease & 3 \\
\hline Up to 90-years-old & 6 \\
\hline Metastatic solid tumor & 6 \\
\hline Acquired immunodeficiency syndrome & 1 \\
\hline
\end{tabular}

that which persisted for $48 \mathrm{~h}$ and then spontaneously resolved. Creatinine and a blood count were performed postoperatively. All patients received antibiotics.

The studied parameters concerned the age, the average weight of the adenoma, the duration of the intervention, the weight of the enucleated tissue, the pre-existing co-morbidities, the operative indication and the postoperative complications. Complications were classified as immediate, early, or late, depending on whether they occurred during the procedure, in the month following surgery, or later. The Charlson Comorbidity Index (Table 1) was used for the assessment of comorbidity factors. Report of complications was made on the basis of the modified Clavien's classification system (Table 2). Complication grade distributions based on the different Charlson comorbidity indexes were compared using chi-square test and $p$ value $<0.05$ was considered significant statistically.

\section{Results}

Out of 312 prostatectomies carried out during the study period, 100 cases of complications were noted, giving a rate of $32.05 \%$.

The average age of patients was 69,95 years \pm 9.10 $[50 ; 86]$.

The average weight of the adenoma was 113, $25 \mathrm{~g} \pm$ $39.52[40 ; 186]$.

The average operating time was $107 \mathrm{mn} \pm 33.91$ [60; 180].

Most patients (78\%) had a comorbidity Index of Charlson of at least 2.

The characteristics of patients are resumed in Table 3.

Complicated $\mathrm{BPH}$ was the main operative indication (71\%). Recurrent urinary retention accounted for $83 \%$ of these complications. In Table 4, the different indications for prostatectomy are presented.

Patients who had a urinary catheter before they

Table 2: Classification of complications on the basis of modified Clavien-Dindo system [5].

Grade I: Any deviation from normal postoperative course without the need for pharmacological treatment or surgical, endoscopic or interventional radiology. The accepted therapies are drugs such as antiemetic, antipyretics, analgesics, diuretics, electrolytes and physiotherapy.

Grade II: Complication requiring pharmacological treatment with drugs other than those used in Grade I complication (including hematuria requiring blood transfusion)

Grade III: Complications requiring surgery, endoscopy or interventional radiology

Grade Illa: Intervention carried out under any form of anesthesia other than general anesthesia (including performing a cystostomy)

Grade IIIb: Intervention performed under general anesthesia

Grade IV: Life-threatening complications (including central neurological complications)

Grade IVa: Dysfunction of a single organ. Including renal failure supported by dialysis

Grade IVb: Multiple organ dysfunction with Intensive Care Unit admission

Grade V: Death of the patient 
Table 3: Characteristics of patients presenting at least one postoperative complication $(n=100)$.

\begin{tabular}{|l|l|l|}
\hline Parameters & Mean \pm SD & Min-Max \\
\hline Age & $69.95 \pm 9.1$ & $50-86$ \\
\hline IPSS & $22.4 \pm 4.5$ & $17-30$ \\
\hline QoL & $4.8 \pm 0.6$ & $3-6$ \\
\hline Prostate size (g) & $113.25 \pm 39.5$ & $40-186$ \\
\hline PSA (ng/ml) & $3.66 \pm 4$ & $0.68-12$ \\
\hline Charlson Comorbidity Index & $2 \pm 2$ & $0-4$ \\
\hline Preoperative hemoglobin $(\mathrm{g} / \mathrm{dl})$ & $10 \pm 3$ & $7-11$ \\
\hline Preoperative creatinine $(\mu \mathrm{mol} / \mathrm{l})$ & $110 \pm 3.5$ & $60-300$ \\
\hline Duration of operation (mn) & $107 \pm 33.9$ & $60-180$ \\
\hline Urinary catheter duration $(\mathrm{days})$ & $10 \pm 4$ & $7-14$ \\
\hline Hospital stay duration (days) & $10 \pm 3$ & $7-28$ \\
\hline Follow-up duration (months) & $12 \pm 4$ & $6-18$ \\
\hline Postoperative hemoglobin $(\mathrm{g} / \mathrm{dl})$ & $11 \pm 2$ & $9-13$ \\
\hline Postoperative creatinine $(\mu \mathrm{mol} / \mathrm{l})$ & $90 \pm 3.5$ & $60-160$ \\
\hline
\end{tabular}

IPSS: International Prostatic Symptoms Scale; UTI: Urinary Tract Infection; SD: Standard Deviation.

Table 4: Different indications of prostatectomy.

\begin{tabular}{|l|l|l|}
\hline Indications of open simple prostatectomy & $\mathbf{n}$ & $\mathbf{\%}$ \\
\hline BPH with complication & $\mathbf{7 1}$ & $\mathbf{7 1 \%}$ \\
\hline Recurrent urinary retention & 59 & $59 \%$ \\
\hline Recurrent urinary tract infections & 7 & $7 \%$ \\
\hline Gross hematuria & 3 & $3 \%$ \\
\hline Renal insufficiency & 1 & $1 \%$ \\
\hline Concurrent bladder calculi & 1 & $\mathbf{1 \%}$ \\
\hline Failure of medical treatment & $\mathbf{2 9}$ & $\mathbf{2 9} \%$ \\
\hline Total & $\mathbf{1 0 0}$ & $\mathbf{1 0 0 \%}$ \\
\hline
\end{tabular}

were admitted into the operative theatre for surgery were 20 times more likely to develop a post-operative complication $(O R=20.06)$.

Seventy percent of patients exhibited at least one complication and the majority of these complications (87\%) were classified as Grade 1 or 2 according to the modified Clavien's classification System (Table 2).

\section{Discussion}

Out of 312 prostatectomies carried out during the study period, 100 cases of complications were noted during twenty-four months, giving a complication rate of $32.05 \%$ or approximatively four complications after $\mathrm{BPH}$ surgery per month. BPH surgery is the most surgical procedure performed in our urology division comparatively with endoscopic procedures. This prostatic surgery mainly concerned elderly subjects, with an average age of 70 , comparable to data from recent series, confirming that this pathology is that of the elderly. Thus Salako, et al. in their study found an average age of 67 years with a complication rate of $36.4 \%$, slightly higher than ours which was $32 \%$ [9]. The classic open prostatectomy performed in our department was performed by transvesical route. Hryntschack described the transvesical open prostatectomy, with the principles and steps that are now followed in most urological centres [10]. It is the same technique performed in all our patients. Of all the modalities for treating symptoms of lower urinary tract (LUTS) due to benign prostatic hyperplasia (BPH), prostatectomy provides the highest symptomatic improvement and the lowest failure rate [11]. If in western countries with advanced technology, it is reserved for BPH of $80 \mathrm{~g}$ and more [10], in our context it is the main option of treatment. Surgery of $\mathrm{BPH}$ is indicated in presence of symptomatic BPH with obstructive or infectious complications or in case of failure of a well-conducted medical treatment using alpha-blockers, the 5-alpha-reductase inhibitors or phytotherapy. In the present study, complications indicated surgery for $60 \%$ of patients and $29 \%$ of patients were operated because of the failure of well conducted medical treatment.

In our study the complication rate was $32.05 \%$. It is close to the $28 \%$ reported by a recent American prospective study [12]. Rates of $40.1 \%$ and $17.3 \%$ were reported in African and European series respectively $[13,14]$. Indeed, prostatectomy as an open surgery is known to have higher morbidity compared to other surgical means of symptomatic BPH. Immediate complications (15\%) were mainly represented by per operative bleeding with the need for blood transfusion (complication Grade II). Transfusion rates of 7 to $14 \%$ were reported in the literature $[15,16]$. We have reported a blood transfusion rate of $13 \%$ among our patients. During surgery, haemostasis consists in the ligation of bleeding arteries per operatively at 5 o'clock and 7 o'clock as described by some authors [17]. A link between the risk of complication and the volume of the prostate could not be determined in this study (Table 5). Traction of the balloon of urethral catheter into the prostatic fossa and haemostasis secured by ligature of bleeding arteries at the bladder neck help in securing the haemostasis [18]. Fever requiring antipyretic administration came as a head of complications grade I (9\%). This value was influenced by antibiotherapy post operatively. Other causes of fever like urosepsis, urinary infections, orchi-epididymitis, wound suppurations were eliminated and taken into consideration in other grading of complications as shown in Table 6. Urinary infections were noted in $21 \%$ of cases and E.coli was isolated in $76.19 \%$ of cases. Patients older than 75 -years-old were most at risk and ascending infection through urinary catheter can explain the post-operative bacteriuria [19]. It requires antibiotherapy in our case (Grade II) other factors like long duration in the hospital, long preoperative hospital admission for more than two days and the time of exposure to the urinary catheter have been identified as risk factors [20]. Parietal suppuration requires dressing at the bed side of the patient, swab 
Table 5: Comparison of complications of prostatectomy, classified according to the modified Calvien system, between patients with various Charlson comorbidity scores.

\begin{tabular}{|c|c|c|c|c|c|}
\hline & \multicolumn{3}{|c|}{ Charlson Comorbidity Index } & \multicolumn{2}{|c|}{ Test for comparison } \\
\hline & Total & $\mathrm{CCl}<1$ & $\mathrm{CCl} \geq 2$ & Chi square & $P_{\text {_ value }}$ \\
\hline Total patients & 312 & $64(21)$ & $248(79)$ & & \\
\hline Grade I & 29 & $8(8)$ & $21(21)$ & 2.747 & 0.253 \\
\hline Grade II & 55 & $12(12)$ & $33(33)$ & 2.853 & 0.240 \\
\hline Grade III & 10 & $4(4)$ & $6(6)$ & NA & NA \\
\hline Grade IV & 4 & $1(1)$ & $3(3)$ & NA & NA \\
\hline Grade V & 2 & $0(0)$ & $2(2)$ & NA & NA \\
\hline Total number of complications (\%) & $100(100)$ & $22(22)$ & $78(78)$ & 0.212 & 0.899 \\
\hline
\end{tabular}

Table 6: Complications of open prostatectomy classified according to modified Clavien system.

\begin{tabular}{|c|c|c|c|}
\hline Complications & Grade & n (\%) & Management \\
\hline \multirow[b]{2}{*}{ Immediate complications } & II. Peroperative bleeding & $13(13)$ & Blood transfusion \\
\hline & IVb. Tensional instability & $02(2)$ & Adrenaline, Intensive unit care \\
\hline \multirow{12}{*}{ Early complications } & I. Fever & $09(9)$ & Antipyretics \\
\hline & $\begin{array}{l}\text { I. Transient elevation of serum } \\
\text { creatinine }\end{array}$ & $06(6)$ & Hydration \\
\hline & I. Failed voiding trial without catheter & $04(4)$ & Indwelling bladder catheter \\
\hline & I. Stress incontinence & $04(4)$ & Muscarinic receptor antagonist \\
\hline & I. Transient hematuria & $06(6)$ & Bladder washout, irrigation \\
\hline & II. Urinary tract infection & $21(21)$ & Antibiotic therapy \\
\hline & II. Wound infection & $10(10)$ & $\begin{array}{l}\text { Antibiotic therapy, antiseptic wound } \\
\text { dressing }\end{array}$ \\
\hline & II. Epididymo-orchitis & $08(8)$ & Antibiotic therapy \\
\hline & II. Vesico-parietal fistula & $05(5)$ & Prolonged bladder catheter \\
\hline & Illa.Vesico-parietal fistula & $05(5)$ & $\begin{array}{l}\text { Secondary suturing under local } \\
\text { anesthesia }\end{array}$ \\
\hline & IVa. Urosepsis & $02(2)$ & $\begin{array}{l}\text { Indwelling bladder catheter removal, } \\
\text { Urine and blood culture, Antibiotic } \\
\text { therapy, Intensive unit care admission }\end{array}$ \\
\hline & V. Death & $02(2)$ & - \\
\hline \multirow{2}{*}{ Late complications } & IIla. Urethral stenosis & $02(2)$ & $\begin{array}{l}\text { Suprapubic cystostomy, differed } \\
\text { anastomotic uretroplasty }\end{array}$ \\
\hline & Illb. Textiloma & $01(1)$ & Foreign body removal \\
\hline
\end{tabular}

and antibiotherapy (grade II), is one of the specific complications for of open surgery. It was seen in about $10 \%$ of cases. Other studies reported the rates of $2.5 \%$ to $4.3 \%$ [21]. This high rate of infection in our study can be explained by non-sterile urine before intervention for all the patients because many of them have previously urinary catheters in place. Mortality represent grade $\mathrm{V}$ complication, it happens during immediate postoperation in $2 \%$ of our patients. It was estimated at less than $0.25 \%$ in one contemporary series [22]. The situation in our context could be explained by the fact that there was already an associated comorbidity factors pre-operatively. Lates complications were rare in our series (3\%) with one case of urethral stenosis and one case of textiloma. They are all rare complications but well known [23]. These late complications were managed respectively by performing anastomotic urethroplasty and foreign body removal in the bladder and postoperative course were uneventful for the two patients.

\section{Conclusions}

Open transvesical prostatectomy complications are common in our setting. They are mostly Grade I and II of Clavien classification. Two cases of high-Grade $\mathrm{V}$ complication (death) were noted. The appearance or the disappearance of post-operative complications depend on the operator experience and on the comorbidity, factors carried by the patient. The frequency of postoperative death is still high and depends on multiple factors. The immediate cause of death still difficult to established without autopsy.

\section{References}

1. Olapade-Olaopa E, Adebayo S, Takure A, Shittu O, Okeke L (2014) Open prostatectomy for BPH in contemporary 
urological practice in Ibadan, Nigeria. Afr J Urol 2: 114-118.

2. Elshal AM, El-Nahas AR, Barakat TS, Elsaadany MM, ElHefnawy AS (2013) Transvesical open prostatectomy for benign prostatic hyperplasia in the era of minimally invasive surgery: Perioperative outcomes of a contemporary series. Arab J Urol 11: 362-368.

3. Condie JD, Cutherell L, Mian A (1999) Suprapubic prostatectomy for benign prostatic hyperplasia in rural Asia: 200 consecutive cases. Urol 54: 1012-1016.

4. Clavien PA, Sanabria JR, Strasberg SM (1992) Proposed classification of complications of surgery with examples of utility in cholecystectomy. Surgery 111: 518-526.

5. Dindo D, Demartines N, Clavien PA (2004) Classification of surgical complications: A new proposal with evaluation in a cohort of 6336 patients and results of a survey. Ann Surg 240: 205-213.

6. Mitropoulos D, Artibani W, Graefen M, Remzi M, Rouprêt M, et al. (2012) Reporting and Grading of complications after urologic surgical procedures: An ad hoc EAU guidelines panel assessment and recommendations. Eur Urol 61: 341-349.

7. Mitropoulos D, Artibani W, Biyani CS, Bjerggaard Jensen J, Rouprêt M, et al. (2017) Validation of the Clavien-Dindo grading system in urology by the EAU guidelines ad hoc panel. Eur Urol Focus 4: 608-613.

8. Charlson ME, Pompei P, Ales KL, MacKenzie CR (1987) A new method of classifying prognostic comorbidity in longitudinal studies: Development and validation. J Chronic Dis 40: 373-383.

9. Salako A, Badmus T, Owojuyigbe A, David R, Ndegbu C, et al. (2016) Open prostatectomy in the management of benign prostate hyperplasia in a developing economy. Open Journal of Urology 6: 179-189.

10. Tubaro A, de Nunzio $C$ (2006) The current role of open surgery in BPH. EAU-EBU Update Series 4: 191-201.

11. Jepsen JV, Bruskewitz RC (1998) Recent developments in the surgical management of benign prostatic hyperplasia. Urol 51: 23-31.

12. Pariser JJ, Pearce SM, Patel SG, Bales GT (2015) National Trends of simple prostatectomy for benign prostatic hyperplasia with an analysis of risk factors for adverse perioperative outcomes. Urol 86: 721-725.
13. Oranusi CK, Nwofor A, Oranusi IO (2012) Complication rates of open transvesical prostatectomy according to the Clavien-Dindo classification system. Niger J Clin Pract 15: 34-37.

14. Gratzke C, Schlenker B, Seitz M, Karl A, Hermanek P, et al. (2007) Complications and early postoperative outcome after open prostatectomy in patients with benign prostatic enlargement: Results of a prospective multicenter study. J Urol 177: 1419-1422.

15. Kuntz RM, Lehrich K, Ahyai SA (2008) Holmium laser enucleation of the prostate versus open prostatectomy for prostates greater than 100 grams: 5-year follow-up results of a randomised clinical trial. Eur Urol 53: 160-166.

16. Meier DE, Tarpley JL, Imediegwu O, Olaolorun DA, Nkor SK, et al. (1995) The outcome of suprapubic prostatectomy: A contemporary series in the developing world. Urol 46: 4044.

17. Okwudili OA (2018) 42 Consecutive open suprapubic prostatectomies without blood transfusion or continuous bladder irrigation. J Urol Ren Dis 3: 1-8.

18. Mehdi Shirazi, Ghaffari S, Hassanpour A, Salehipoor M, Afrasiabi MA (2009) Urethral catheter traction reduces bleeding compared with suturing of prostatic vesical junction during suprapubic prostatectomy: A randomized clinical trial study. Urol 74: 137-141.

19. Ibrahim Al, Bilal NE, Shetty SD, Patil KP, Gommaa H (1993) The source of organisms in the post-prostatectomy bacteriuria of patients with pre-operative sterile urine. $\mathrm{Br} \mathrm{J}$ Urol 72: 770-774.

20. Colau A, Lucet JC, Rufat P, Botto H, Benoit G, et al. (2001) Incidence and risk factors of bacteriuria after transurethral resection of the prostate. Eur Urol 39: 272-276.

21. Delongchamps NB (2012) Treatment of BPH by endourologic procedures and open prostatectomy: Literature review of french comity of men's lower urinary tract symptom, French Association of Urology. Prog Urol 22: 73-79.

22. Varkarakis I, Kyriakakis Z, Delis A, Protogerou V, Deliveliotis C (2004) Long-term results of open transvesical prostatectomy from a contemporary series of patients. Urol 64: 306-310.

23. Würnschimmel E, Lipsky H (1992) Urethral stricture after TURP and transvesical prostatectomy. Urol 31: 374-377. 